Research Article

\title{
Spatial Distribution and Temporal Trends in the Daily Precipitation Concentration across the Yarlung Tsangpo River Basin: Eastern Himalaya of China
}

\author{
Mengtao Zhu $\mathbb{D}^{1},{ }^{1}$ Meng Li $\left(\mathbb{D},{ }^{2}\right.$ Chunyu Liu $\left(\mathbb{D},{ }^{1}\right.$ Yinfei Wang $\mathbb{D}^{1},{ }^{1}$ Jiqiu Li $\left(\mathbb{D},{ }^{1}\right.$ \\ and Yungang $\mathrm{Li} \mathbb{C}^{1,3}$ \\ ${ }^{1}$ Yunnan Key Laboratory of International Rivers and Transboundary Eco-Security, Yunnan University, Kunming 650091, China \\ ${ }^{2}$ Yunnan Climate Center, Kunming 650034, China \\ ${ }^{3}$ Asian International Rivers Center, Yunnan University, Kunming 650091, China
}

Correspondence should be addressed to Yungang Li; ygli@ynu.edu.cn

Received 28 July 2020; Accepted 4 December 2020; Published 15 December 2020

Academic Editor: Luis Gimeno

Copyright ( 2020 Mengtao Zhu et al. This is an open access article distributed under the Creative Commons Attribution License, which permits unrestricted use, distribution, and reproduction in any medium, provided the original work is properly cited.

Understanding the temporal inequality in precipitation is of great importance for water resource management, environmental risk management, and ecological conservation. This study investigated the spatial patterns and trends of the daily precipitation concentration over the Yarlung Tsangpo River Basin using the concentration index (CI) and the Lorentz asymmetric coefficient (LAC). A Mann-Kendall test and Hurst's rescaled range analysis were used to detect the change in CI trends. The CI ranged from 0.58 to 0.65 , suggesting that a quarter of the rainiest days contributed approximately $69-78 \%$ of the total precipitation. The LAC analysis indicated that the nonuniform distribution of precipitation was mainly attributed to a large proportion of days with light rainfall. Compared with that of the central region, the daily precipitation in the western and eastern regions was more irregular. At a seasonal scale, the dry season had a less homogeneous spatial distribution of CI compared to that of the wet season. Most areas exhibited no significant trends in CI from 1970 to 2017. A quarter of the stations presented a significant downward trend in CI, which were primarily found in the central and northern regions. In addition, the future trends of CI in most areas mostly agree with those of the current state; however, the majority of stations exhibited an uneven precipitation distribution in the dry season.

\section{Introduction}

Precipitation is a fundamental process of the water cycle $[1,2]$ and shows high temporal and spatial variability $[3,4]$. As the climate changes, the most notable variation in precipitation events will likely be observed in their intensity, frequency, and duration [5]. Numerous studies have reported that precipitation extremes appear to intensify with global warming [6-9]. Precipitation extremes are directly responsible for floods, droughts, landslides, and soil erosion, which have notable impacts on both the environment and society $[10,11]$. Therefore, the analysis of the temporal inequality in precipitation is a subject of great interest [12].

The precipitation concentration refers to the temporal heterogeneity of precipitation, which is applicable in research of water-related environmental risks $[13,14]$. For instance, high precipitation concentrations, meaning a small number of rainy days with a large amount of total precipitation, could trigger floods and droughts $[15,16]$. Many indices were introduced to quantify the temporal precipitation concentration. To quantify precipitation heterogeneity on a monthly scale, Oliver [17] developed the precipitation concentration index (PCI) using the monthly precipitation data within a given year. Zhang and Qian [18] proposed the precipitation concentration degree (PCD) and precipitation concentration period (PCP) to represent the intra-annual distribution of total precipitation based on vector analysis. To evaluate daily precipitation irregularity in a given year, Martin Vide [19] proposed the concentration index $(\mathrm{CI})$ to determine the percentage of precipitation contributed by the days falling in each rainfall class. The CI has been widely applied to study rainfall on both global [12] 
and regional scales in multiple places, such as Spain [19], Iran [20], Malaysia [21], Italy [22], Algeria [23], India [24], Chile [25], Russia [26], Bangladesh [13], and China [27, 28].

The Yarlung Tsangpo River Basin (YTRB) is in the eastern Himalaya of China, which contains great environmental diversity (e.g., high mountains, glaciers, permafrost, and seasonally frozen soil) and is sensitive to climate change as indicated by the observed retreat of glaciers, permafrost degradation, desertification, and land-use changes [29-31]. In the last three decades, natural disasters related to precipitation extremes, such as floods, droughts, glacier debris flows, and landslides, have become more severe and frequent [32]. Thus, it is crucial to understand the distribution and patterns of precipitation concentration because of the potential consequences of precipitation extremes and natural disasters in the YTRB.

Climate change has been investigated in the YTRB with regard to diverse aspects. A remarkable warming trend was observed from 1970 to 2017 [33]. The warming trend was found to be up to $0.32^{\circ} \mathrm{C} /$ decade, while annual precipitation was found to increase by $6.32 \mathrm{~mm} /$ decade from 1961 to 2014 [34]. Fan et al. [35] found that annual rainfall amounts and the number of rainy days significantly increased from 1958 to 2010 , indicating that the increasing number of rain days is one possible cause of the increases in annual rainfall amounts. Sang et al. [36] reported that the number of precipitation extremes and the amount of rainfall (25-50 mm/d) decreased from 1973 to 2011.

Although previous studies have investigated the changes in mean precipitation and precipitation extremes, few studies have focused on temporal inequalities in precipitation, particularly with regard to the spatial patterns and trends of the daily precipitation concentration. The CI based on the Lorenz curve has been widely used in the studies on daily precipitation concentration in many regions around the world, which has also been applied to compare the precipitation concentration among different regions. In addition, the Lorenz asymmetry coefficient (LAC) is a supplementary indicator of the CI. It measures the contribution of different precipitation classes to the precipitation heterogeneity. Thus, the objectives of this study were to (1) analyze the spatial distribution of the daily precipitation concentration using the CI and the LAC, (2) detect trends in the CI using the Mann-Kendall trend test, and (3) predict the possible CI trend based on the Hurst's rescaled range analysis.

\section{Data and Methods}

2.1. Study Area. The YTRB is in the Qinghai-Tibet Plateau and is one of the highest major river basins in the world, with a mean elevation of over $4000 \mathrm{~m}$. The YTRB is roughly $2229 \mathrm{~km}$ long and covers an area of $2.4 \times 10^{5} \mathrm{~km}^{2}$ [37] (Figure 1). The geographical location and topographic characteristics of the YTRB play a major role in the climate diversity of the upper, middle, and lower reaches of the basin. The surrounding vegetation in the basin changes from alpine meadow in the upstream region to alpine grassland in the midstream region to alpine forest in the downstream region [30]. Annual precipitation in the downstream region is more than $2000 \mathrm{~mm}$ and decreases to less than $300 \mathrm{~mm}$ in the upper stream region. The moisture from Bengal Bay is transported by Indian monsoons and is the primary source of precipitation in the region [38]. The climate is characterized by a distinct rainy season (June to September) in which approximately $60-80 \%$ of the annual precipitation occurs [37]. The Yarlung Tsangpo River has numerous tributaries and is an abundant freshwater resource that is important for Tibet and other downstream countries $[39,40]$.

2.2. Precipitation Data. Daily precipitation data at 16 meteorological stations across the YTRB were provided by the National Meteorological Information Center (NMIC; http:// data.cma.cn). The quality of the dataset was verified by the NMIC when it was released, and quality control and homogeneity assessments were subsequently performed [33]. To make the best use of available data and obtain the best spatial coverage, 14 stations within the YTRB and 2 stations outside the basin were selected for subsequent analysis. The locations of the 16 meteorological stations are shown in Figure 1. The recording periods of the stations varied in duration; however, most stations had data available from 1970 to 2017. The specific information of the 16 stations is shown in Table 1.

2.3. Precipitation CI. The daily precipitation CI was computed using the approach proposed by [19], based on the Lorenz diagrams and the Gini index. The cumulative percentage of rainy days $(X)$ was plotted against the associated cumulative percentage of rainfall $(Y)$. The Lorenz curve was used to match the empirical pairs of values $(X, Y)$ and had an exponential shape:

$$
Y=a \cdot X \cdot \exp (b \cdot X)
$$

where $a$ and $b$ are constants that can be determined by using the least-squares method.

$$
\begin{aligned}
\ln a & =\frac{\sum x_{i}^{2} \sum \ln y_{i}+\sum x_{i} \sum x_{i} \ln x_{i}-\sum x_{i}^{2} \sum \ln x_{i}-\sum x_{i} \sum x_{i} \ln y_{i}}{N \sum x_{i}^{2}-\left(\sum x_{i}\right)^{2}}, \\
b & =\frac{N \sum x_{i} \ln y_{i}+\sum x_{i} \sum \ln x_{i}-N \sum x_{i} \ln x_{i}-\sum x_{i} \sum \ln y_{i}}{N \sum x_{i}^{2}-\left(\sum x_{i}\right)^{2}}
\end{aligned}
$$




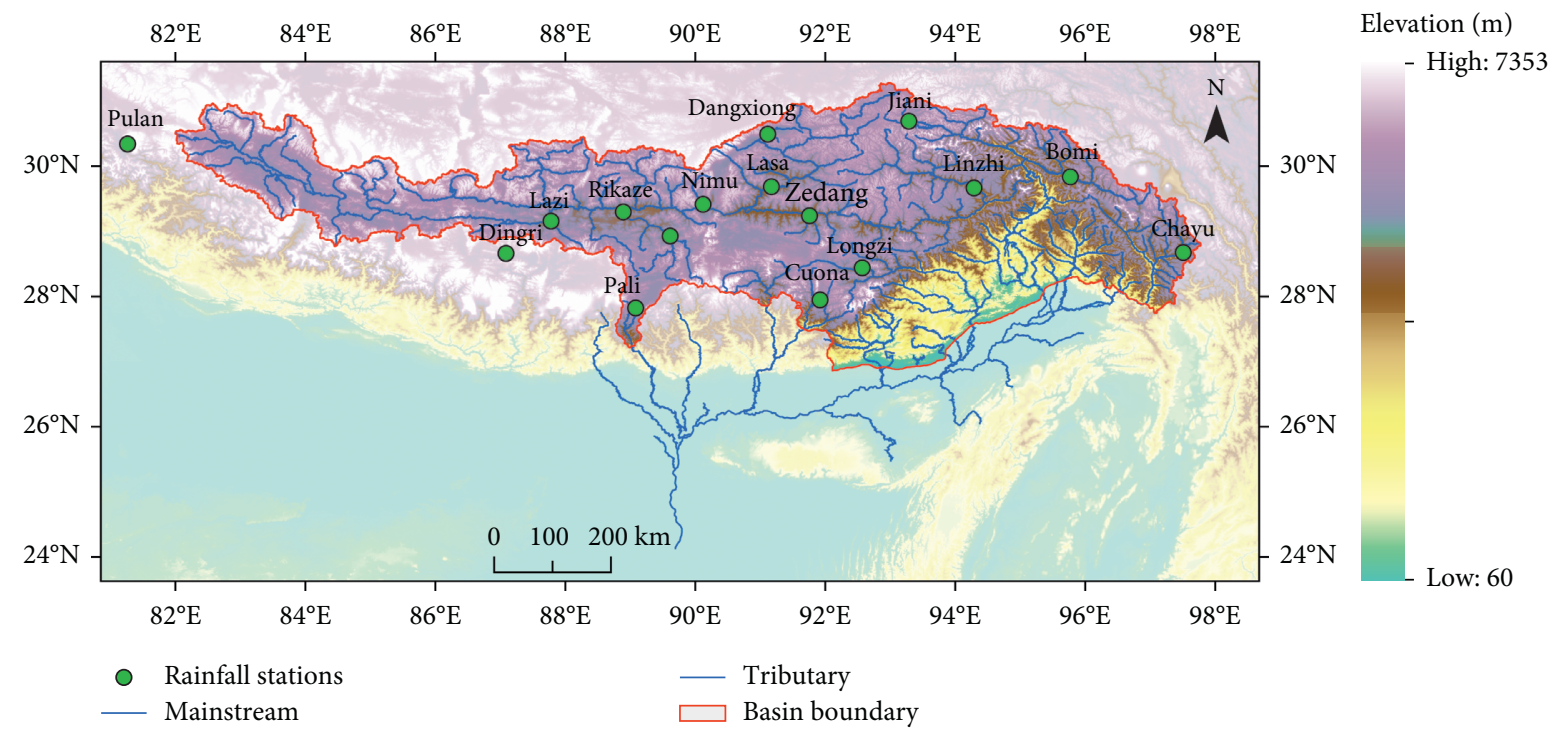

FIgURE 1: The location and distribution of meteorological stations in the YTRB.

TABLE 1: Geographical coordinates, annual mean precipitation (P), coefficient of variation (VC), and mean number of rainy days (N) for the 16 stations considered in this study.

\begin{tabular}{lcccccccc}
\hline ID & Station & Lat $\left({ }^{\circ} \mathrm{N}\right)$ & Long $\left({ }^{\circ} \mathrm{E}\right)$ & Elevation $(\mathrm{m})$ & Study period & $\mathrm{P}(\mathrm{mm})$ & VC $(\%)$ & $N($ day $)$ \\
\hline 55437 & Pulan & 30.28 & 81.25 & 4900 & $1973-2017$ & 156.01 & 33.68 \\
55493 & Dangxiong & 30.48 & 91.1 & 4200 & $1970-2017$ & 468.27 & 20.22 \\
55569 & Lazi & 29.08 & 87.6 & 4000 & $1977-2017$ & 331.94 & 28.47 \\
55578 & Rikeze & 29.25 & 88.88 & 3836 & $1970-2017$ & 428.62 & 25.19 \\
55585 & Nimu & 29.43 & 90.16 & 3809 & $1973-2017$ & 343.10 & 23.08 & 73 \\
55591 & Lasa & 29.66 & 91.13 & 3649 & $1970-2017$ & 445.31 & 21.63 \\
55598 & Zedang & 29.25 & 91.76 & 3552 & $1970-2017$ & 387.83 & 24.78 \\
55664 & Dingri & 28.63 & 87.08 & 4300 & $1970-2017$ & 291.86 & 27.64 & 93 \\
55680 & Jiangzi & 28.91 & 89.6 & 4040 & $1970-2017$ & 285.43 & 22.75 \\
55690 & Cuona & 27.98 & 91.95 & 4280 & $1970-2017$ & 414.46 & 15.71 \\
55696 & Longzi & 28.41 & 92.46 & 3860 & $1970-2017$ & 284.74 & 20.47 \\
55773 & Pali & 27.73 & 89.08 & 4300 & $1970-2017$ & 439.08 & 17.36 \\
56202 & Jiali & 30.66 & 93.28 & 4489 & $1970-2017$ & 729.40 & 12.67 \\
56227 & Bomi & 29.86 & 95.76 & 2736 & $1970-2017$ & 889.61 & 15.69 \\
56312 & Linzhi & 29.66 & 94.33 & 2992 & $1970-2017$ & 689.94 & 17.17 \\
56434 & Chayu & 28.65 & 97.46 & 2328 & $1970-2017$ & 796.95 & 20.80 & 179 \\
\hline
\end{tabular}

Once the constants are obtained, the area under the Lorenz curve can be calculated as follows:

$$
A=\left[\left(\frac{a}{b} e^{b x}\left(x-\frac{1}{b}\right)\right)\right]_{0}^{100} \text {. }
$$

Finally, the CI is defined as follows:

$$
\mathrm{CI}=\frac{(5000-A)}{5000} \text {. }
$$

The greater the CI value, the lower the uniformity, i.e., the more uneven the precipitation (mainly concentrated in a few rainy days).

2.4. Lorenz Asymmetric Coefficient. The CI cannot fully represent the Lorenz Curve as different Lorenz Curves may have the same CI [41, 42]. Therefore, the LAC was introduced to quantitatively define the contribution of different groups to the total heterogeneity [43]. For the ordered sequence, $x_{1} \leq x_{2} \leq \ldots x_{m} \leq \ldots \leq x_{n}$ the LAC can be calculated according to the following equations:

$$
\begin{aligned}
\mathrm{LAC} & =F(\mu)+L(\mu), \\
\delta & =\frac{\mu-x_{m}}{x_{m+1}-x_{m}}, \\
F(\mu) & =\frac{m+\delta}{n} \\
L(\mu) & =\frac{\left(x_{1}+x_{2}+\cdots+x_{m}\right)+\delta x_{m+1}}{\left(x_{1}+x_{2}+\cdots+x_{n}\right)},
\end{aligned}
$$

where $\mu$ is the mean daily precipitation over all rainy days, $n$ is the total number of rainy days, and $m$ is the number of daily precipitation less than $\mu$ [42]. If LAC $<1$, the inequality is attributed to a large number of light 
rainfall events. Correspondingly, if LAC $>1$, the inequality is attributed to a small number of very large rainfall events.

2.5. Trend Analysis. The nonparametric Mann-Kendall test has been widely applied to identify trends in hydrometeorological time series [44]. A positive value of the statistical eigenvalue, $Z$, will represent an upward trend, while a negative value will represent a downward trend. The null hypothesis of no trend should be rejected if $|Z|>Z_{1-\alpha / 2}$, where $\alpha$ is the significance level. Significance levels of 0.1 , 0.05 , and 0.01 were considered in this study. In addition, the Hurst exponent $(\mathrm{H})$ is used as part of a classical test to detect long memory in time series [45]. A well-known method to estimate $\mathrm{H}$ is a rescaled range $(\mathrm{R} / \mathrm{S})$ analysis [46]. Hurst's rescaled range $(\mathrm{R} / \mathrm{S})$ analysis has been widely used in the study of climate change [47-49]. The value of $\mathrm{H}$ ranges from 0 to 1 . When $H=0.5$, the time series is considered to be random. When $0.5<H<1$, a dynamic persistence or trend enhancement series is present. When $0<H<0.5$, resistance to persistence or average recovery is present [50].

\section{Results}

3.1. Spatial Pattern of the Daily Precipitation Concentration. The annual CI and LAC were calculated for 16 meteorological stations in the YTRB for the period 1970-2017. The values of the regression coefficients ( $a$ and $b$ ) and the CI and LAC are presented in Table 2. The annual CI value ranged between 0.58 and 0.65 , suggesting that the lowest values observed are related to regions where $25 \%$ of the rainiest days accounted for $69 \%$ of the total precipitation, while the highest values are associated with places where $25 \%$ of the rainiest days contribute to $78 \%$ of the total precipitation (Table 2). According to the proposed classifications for the CI [11], the averaged value of the CI $(0.60)$ over the YTRB is within high concentration categories, which implied that $25 \%$ of the rainiest days could concentrate more than $70 \%$ of the total precipitation. The annual LAC value ranged between 0.86 and 0.95 , with a median value of 0.89 , which illustrates a high precipitation concentration attributed to a large number of light rainfall events. Figure 2 shows an example of the concentration curves for three stations: Pulan station in the western region (CI: 0.65, LAC: 0.95), Lasa station in the central region (CI: 0.59, LAC: 0.86), and Chayu station in the eastern region (CI: 0.62, LAC: 0.92). Pulan station is located in a frigid zone with an annual rainfall of less than $300 \mathrm{~mm}$. The intra-annual distribution of precipitation is characterized by a few rainy days in the winter season. The Lasa station is located in the valley of a tributary and is found in a semiarid plateau climate with a small amount of annual precipitation $(300-600 \mathrm{~mm})$. Chayu station is located in a subtropical humid zone and has relatively abundant precipitation. The spatial difference in CI indicated that the inequality in precipitation is closely associated with the frequency and intensity of rainfall and not with the amount of precipitation.
TABLE 2: Values for the constants, $a$ and $b$, of the exponential curves, coefficients of determination $\left(R^{2}\right), \mathrm{CI}, \mathrm{LAC}$, and percentage of precipitation contributed by $25 \%$ of the rainiest days (P 25\%).

\begin{tabular}{lcccccc}
\hline Station & $a$ & $b$ & $R^{2}$ & CI & LAC & P 25\% \\
\hline Pulan & 0.023 & 0.036 & 0.96 & 0.646 & 0.946 & 78 \\
Dangxiong & 0.043 & 0.031 & 0.99 & 0.581 & 0.893 & 69 \\
Lazi & 0.037 & 0.033 & 0.99 & 0.594 & 0.894 & 71 \\
Rikeze & 0.036 & 0.033 & 1.00 & 0.590 & 0.861 & 69 \\
Nimu & 0.040 & 0.032 & 0.99 & 0.586 & 0.884 & 70 \\
Lasa & 0.039 & 0.032 & 1.00 & 0.586 & 0.864 & 69 \\
Zedang & 0.034 & 0.034 & 0.99 & 0.599 & 0.876 & 72 \\
Dingri & 0.030 & 0.035 & 0.99 & 0.608 & 0.880 & 72 \\
Jiangzi & 0.033 & 0.034 & 0.99 & 0.602 & 0.891 & 72 \\
Cuona & 0.046 & 0.030 & 0.96 & 0.584 & 0.946 & 72 \\
Longzi & 0.046 & 0.030 & 0.99 & 0.582 & 0.913 & 71 \\
Pali & 0.046 & 0.030 & 0.98 & 0.585 & 0.925 & 71 \\
Jiali & 0.040 & 0.032 & 0.99 & 0.586 & 0.884 & 70 \\
Bomi & 0.029 & 0.035 & 0.99 & 0.612 & 0.907 & 73 \\
Linzhi & 0.029 & 0.035 & 0.99 & 0.611 & 0.900 & 73 \\
Chayu & 0.027 & 0.035 & 0.98 & 0.620 & 0.921 & 74 \\
\hline
\end{tabular}

The CI and LAC values from 1970 to 2017 of the individual stations were spatially interpolated throughout the YTRB based on the Inverse Distance Weighted technique. The high CI values (0.60-0.64) were primarily found in the eastern and western regions, while in the central region, the majority of values fell within $0.58-0.60$ (Figure 3(a)). In the eastern region, the high rainfall intensity observed agreed with the high precipitation concentrations recorded in the area. However, in the western region, high precipitation concentrations were not attributed to remarkably high precipitation but rather to a few rainy days. In the central region, less precipitation and a few days of precipitation contributed to low precipitation concentrations. The values of LAC were less than 1 across the basin, which indicated the nonuniform distribution of precipitation, which was mainly attributed to a large proportion of days with light rainfall (Figure 3(b)).

3.2. Seasonal Distribution of the Daily Precipitation Concentration. Affected by the warm and humid Indian Summer monsoon, the rainy season usually begins in May or June and ends at the end of September or October [51]. Therefore, we divided May to September as the wet season and October to April as the dry season [52]. Figure 4 demonstrates the spatial pattern of the CI and LAC during the wet season (May to September) and dry season (October to April), respectively. The CI values of the wet season ranged from 0.55 (Pali and Jiali stations) to 0.65 (Pulan station), while it varied between 0.57 (Dangxiong station) and 0.65 (Pulan, Pali, and Chayu stations) during the dry season (Figures 4(a) and 4(b)). The spatial pattern of $\mathrm{CI}$ in the wet and dry seasons was very similar to that of the annual pattern. However, the median CI value in the dry season (0.61) was larger than that of the wet season (0.58), which indicated that the heterogeneity of the precipitation distribution was more pronounced in the dry season. The LAC values of the wet season ranged from 0.85 (Rikeze and Zedang station) to 0.94 (Cuona station), while these varied 


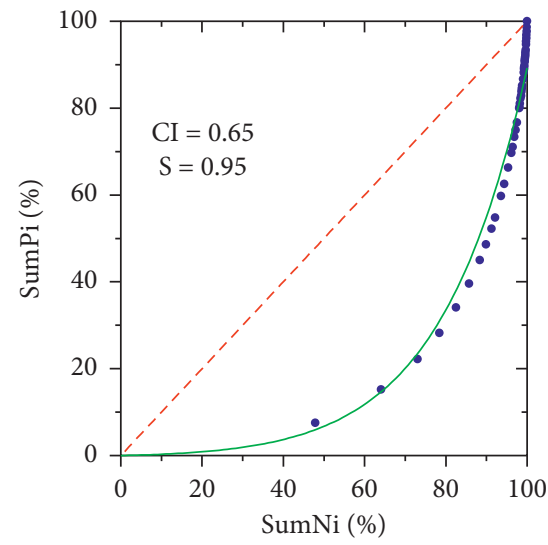

(a)

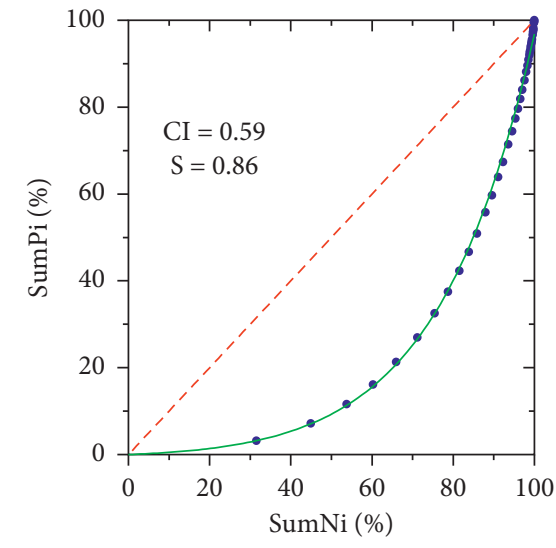

(b)

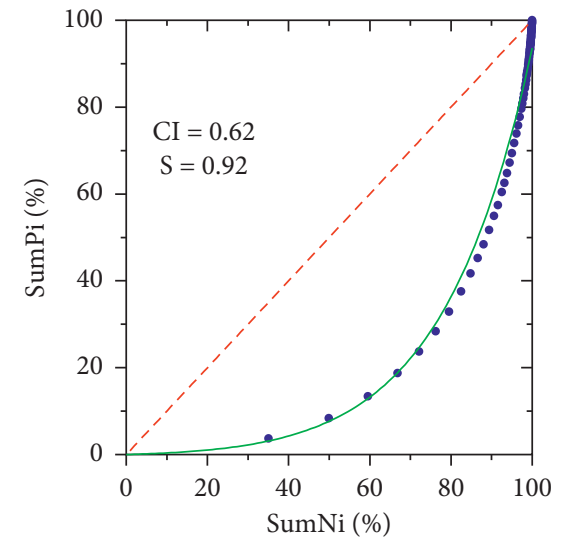

(c)

Figure 2: Concentration curve for the Pulan (a), Lasa (b), and Chayu stations (c) from 1970 to 2017.

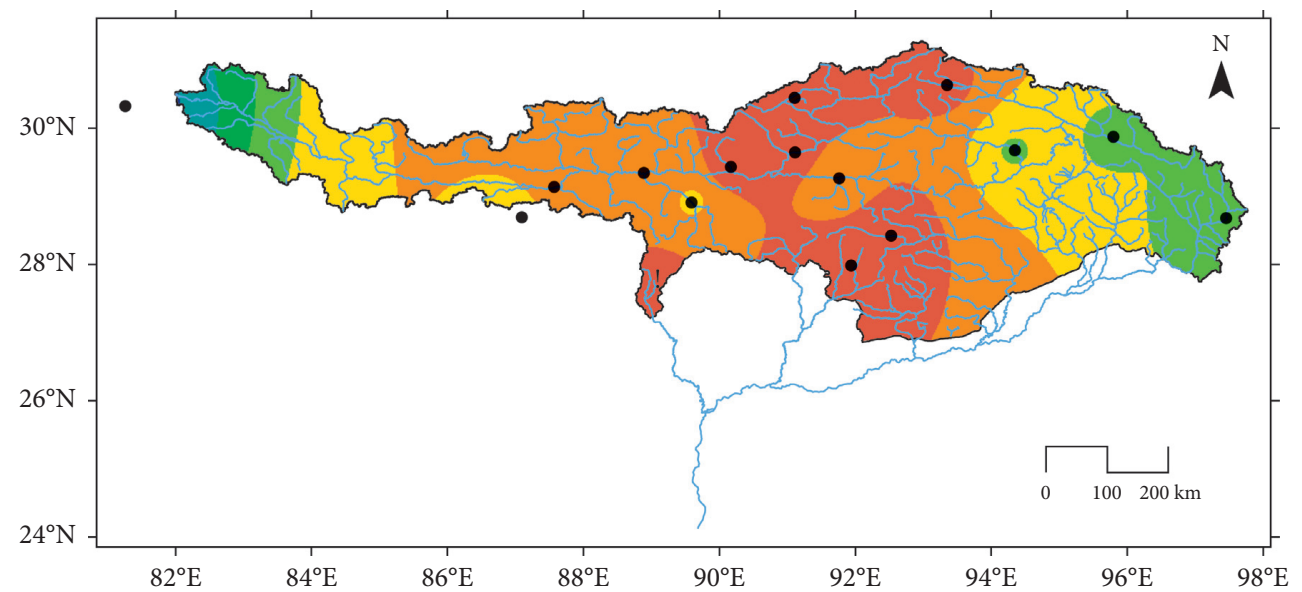

- Stations

- Rivers

CI

Basin boundary

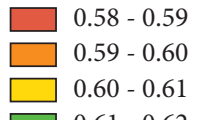

(a)

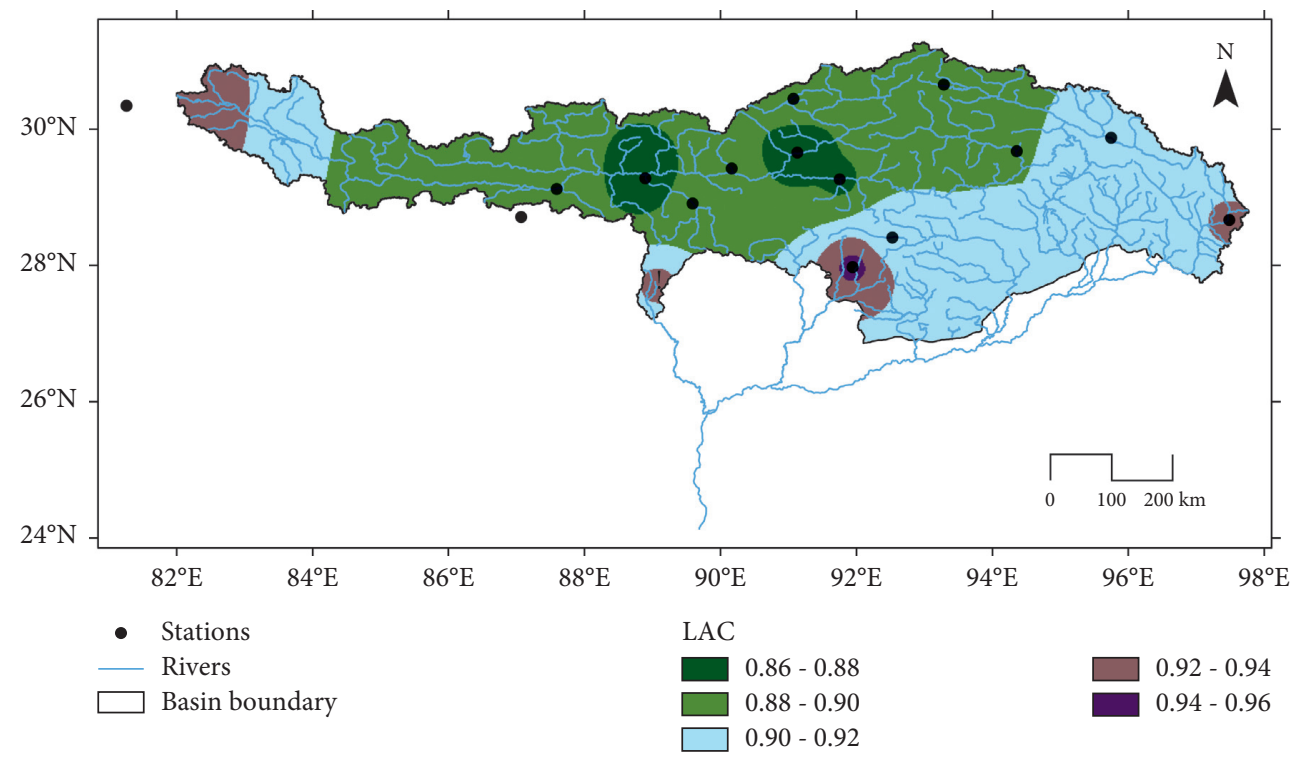

(b)

FIGURE 3: Spatial distribution of annual CI (a) and LAC (b) values. 


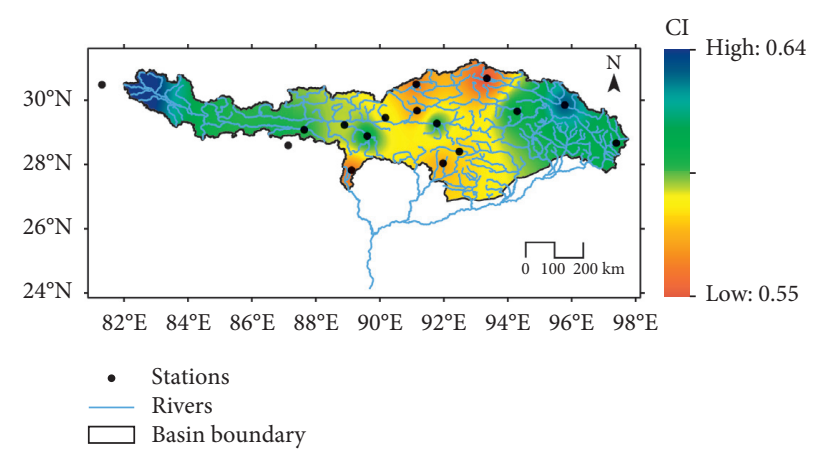

(a)

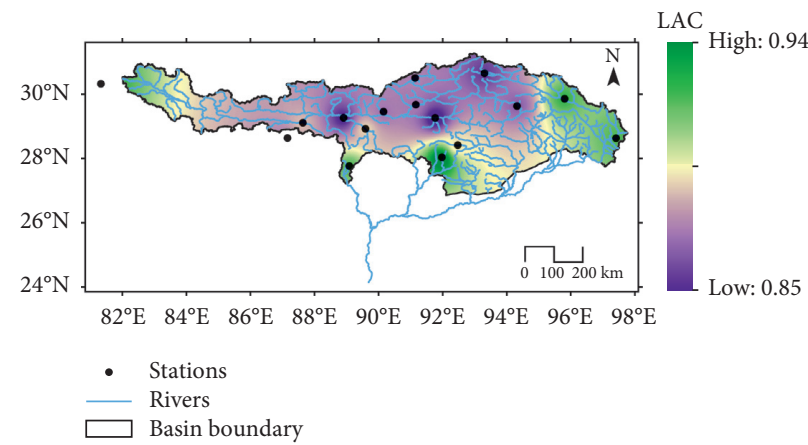

(c)

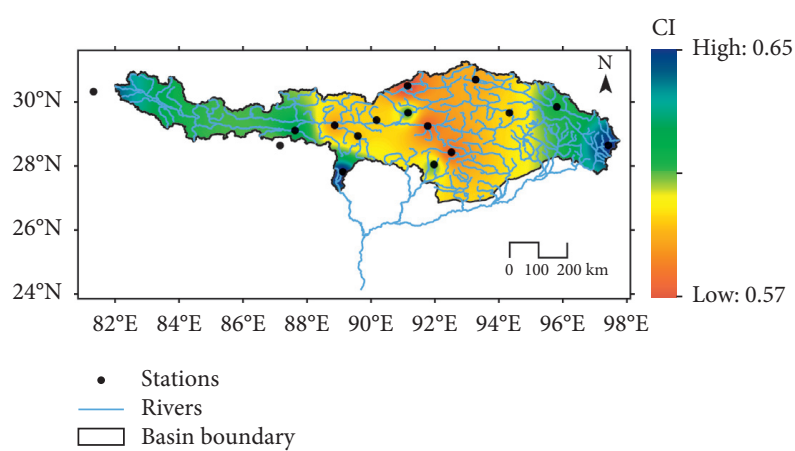

(b)

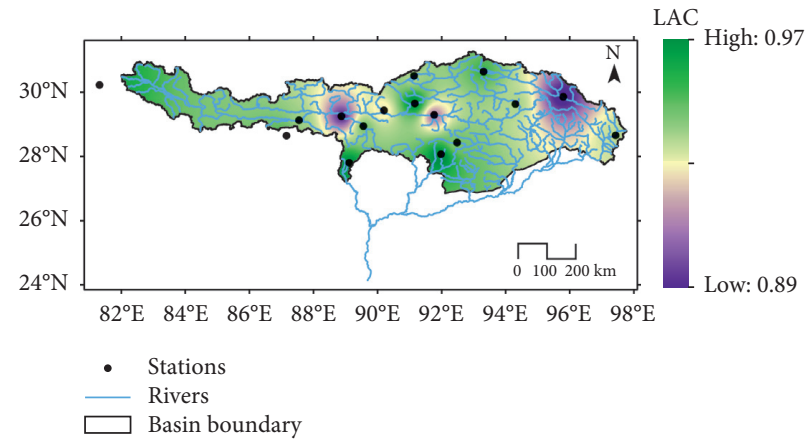

(d)

FIGURE 4: The spatial distribution of the CI and LAC in the wet season and dry season. (a) CI in the wet season; (b) CI in the dry season; (c) LAC in the wet season; (d) LAC in the dry season.

between 0.89 (Rikeze and Bomi stations) and 0.97 (Pali and Lasa stations) in the dry season (Figures $4(\mathrm{c})$ and $4(\mathrm{~d})$ ). Higher LAC values in the dry season were observed when compared with those of the wet season, and the median values in the dry season and wet seasons were 0.94 and 0.89 , respectively.

\subsection{Observed Trends of the Daily Precipitation Concentration.} Figure 5 shows the variation in annual CI, rainy days, and precipitation at the Pulan, Lasa, and Chayu stations, which represent the upper, middle, and lower YTRB, respectively. At Pulan station in the upper region (Figure 5(a)), the CI presented a positive trend; however, the number of rainy days and precipitation showed negative trends, implying that more precipitation fell over a few rainy days. At Lasa station, both the CI and the number of rainy days decreased while precipitation increased, which was attributed to the increases in the precipitation intensity (Figure 5(b)). At Chayu station, the CI, the number of rainy days, and precipitation decreased, suggesting that the decrease in heavy rainfall events was greater than that of the light rainfall events (Figure 5(c)).

Figure 6 shows the number of meteorological stations that presented trends (positive and negative) at different significant levels. On an annual scale and during the wet season, three-quarters of the stations showed no significant trends during the study period. Four stations showed a significant negative trend with confidence levels greater than $90 \%$, which indicated that the intra-annual distribution of precipitation presented a more uniform pattern. These stations are mainly found in the central and northern regions of the basin. However, in the dry season, the number of stations with positive CI trends was greater than that of stations with negative CI trends, although only one station had a significantly positive trend at the $95 \%$ confidence level.

\subsection{Future Trends of the Daily Precipitation Concentration.} Hurst's rescaled range analysis was used to explore the future trends of CI. On an annual scale, the future CI trend was opposite $(0<H<0.5)$ and consistent $(0.5<H<1)$ to the current state accounting for $12.50 \%$ and $81.25 \%$ of all stations, respectively (Figure 7(a)). More concretely, upward trends of the CI continued at 4 stations, while downward trends continued at 9 stations. In addition, 2 other stations showed antipersistent trends, and one station presented an uncertain trend. The future trend of the wet season $\mathrm{CI}$ is similar to that of the annual CI (Figure 7(b)). Moreover, the future trend of the dry season CI, which was opposite and consistent to the current state, accounted for $43.75 \%$ and $56.25 \%$ of all stations, respectively (Figure $7(\mathrm{c})$ ). Specifically, the upward CI trend was enhanced at 5 stations, while downward trends continued at 3 stations. The other 7 stations presented antipersistent trends. Figure 7 shows the spatial distribution of the future CI trend. The precipitation concentration in the western and southern regions of the basin will exhibit an increasing trend, while the precipitation concentration in the eastern and northern regions will 


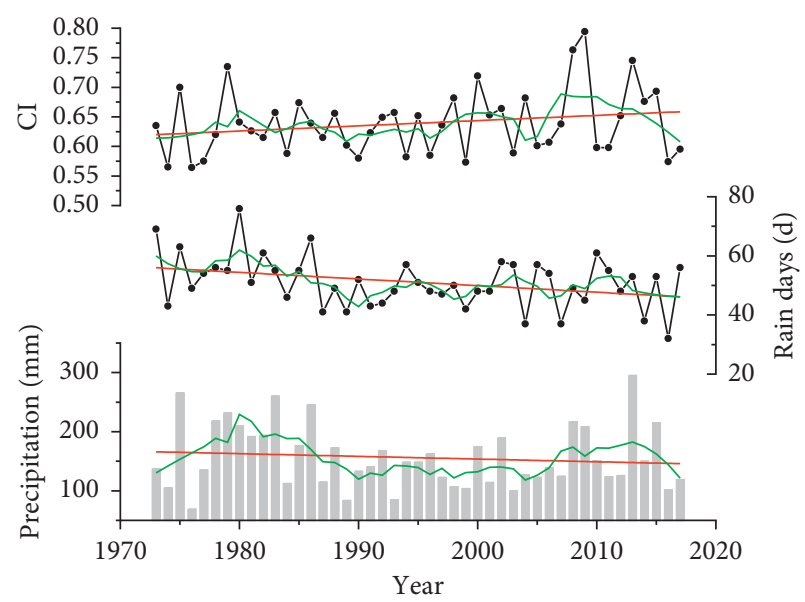

(a)

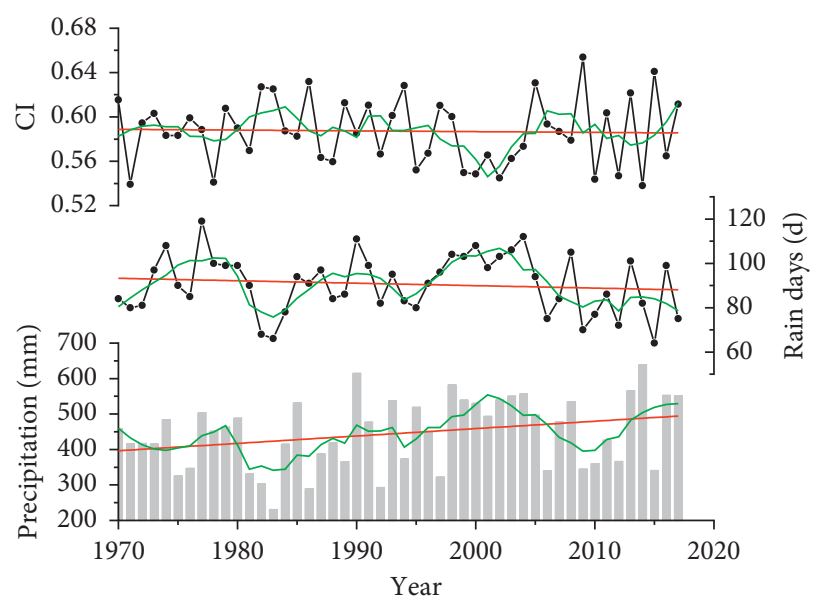

(b)

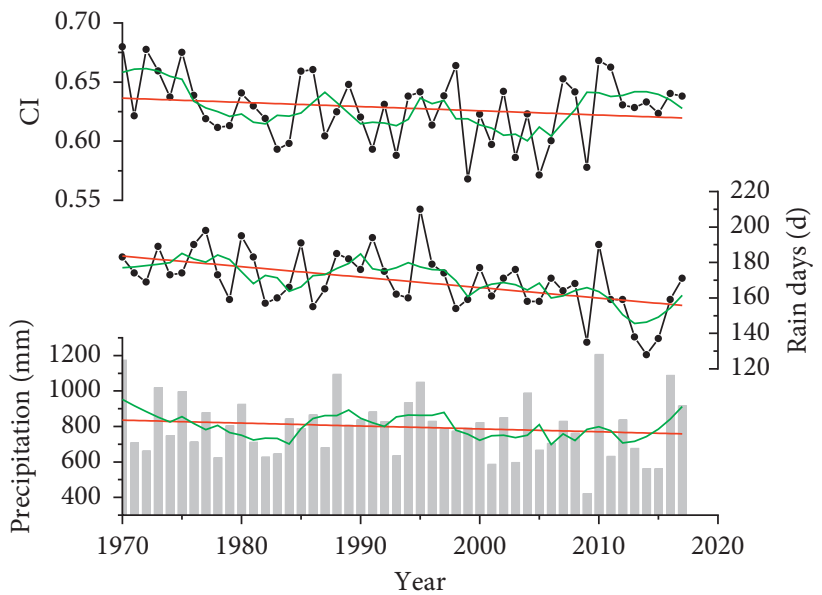

(c)

FIgURE 5: Time series of annual CI, rainy days, and total precipitation amount at the Pulan (a), Lasa (b), and Chayu stations (c). The solid red lines are the corresponding linear trend and the solid green line is 9-year smooth line.

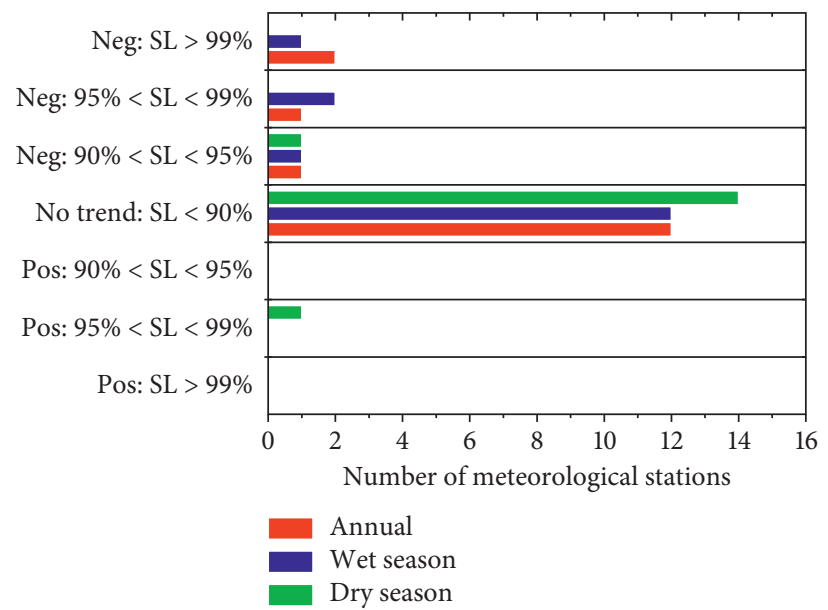

Figure 6: Observed CI trends for different ranges of the significance level.

decrease in the future (Figures $7(\mathrm{a})$ and $7(\mathrm{~b})$ ). It is worth noting that the majority of stations in the YTRB will exhibit irregular and nonuniform distribution in the dry season in the future (Figure $7(\mathrm{c})$ ).

\section{Discussion}

The precipitation concentrations of the YTRB ranged between 0.58 and 0.65 , indicating that a quarter of the rainiest 


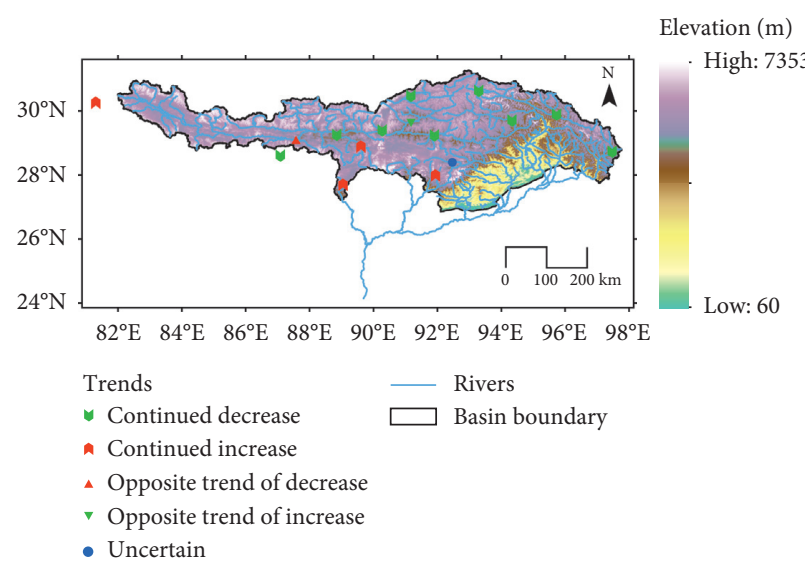

(a)

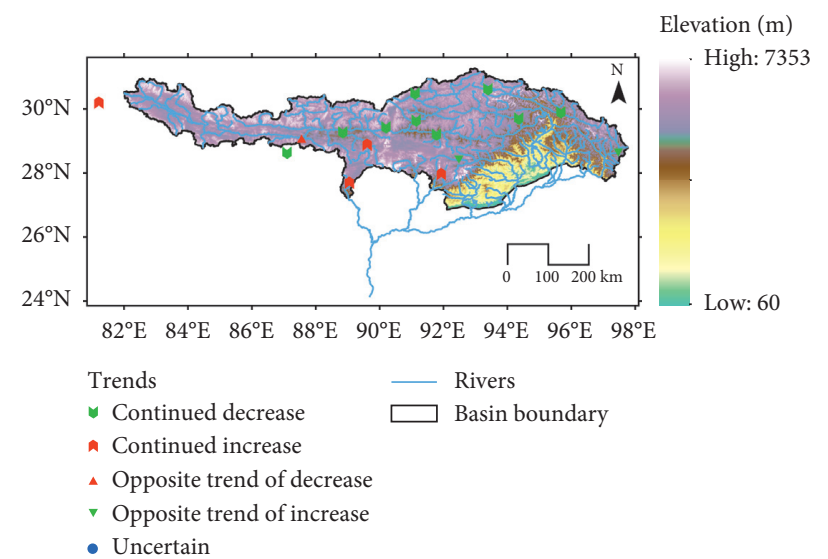

(b)

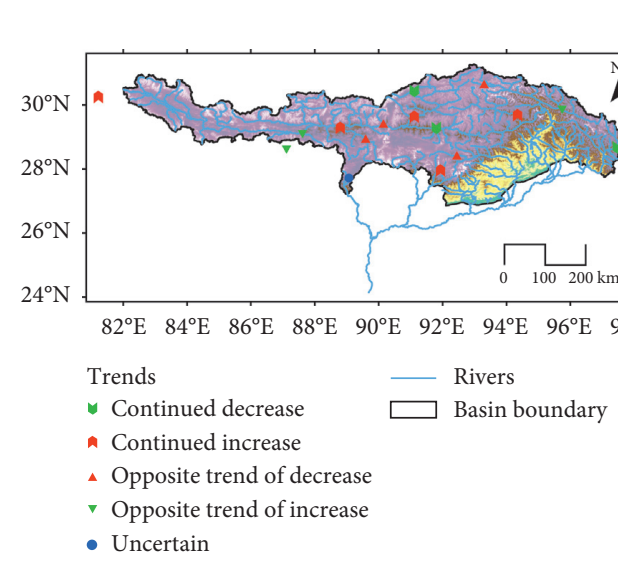

Elevation (m)

(c)

Figure 7: Spatial distribution of future CI. (a) Year. (b) Wet season. (c) Dry season.

days accounted for approximately $69-78 \%$ of the total precipitation. Compared to those reported for different parts of China $[16,28,42,48,53]$ and other regions in the world $[14,21,23,25,54-57]$, the amount of annual rainfall could not accurately reveal the time compression of precipitation, given that similar annual rainfall patterns could present varying daily distributions $[26,58]$.

The spatial pattern of the CI across the YTRB was impacted by water vapor transport, topography, and climate zone. Precipitation is mainly controlled by the South Asian Monsoon (SAM), which weakens from east to west along the Himalayas [59]. Therefore, the intensity, duration, and amount of monsoon rainfall vary from east to west [60]. In addition, the distribution of precipitation in the YTRB is largely influenced by topography [61]. The Himalaya acts as a barrier to the SAM, which brings abundant precipitation that concentrates windward and causes a distinct dry-belt in the leeward side [62]. Therefore, the low CI values were found in the central region that receives less rainfall. Moreover, high CI values were found in the southeast region, which was mainly due to the influence of the topography on local atmospheric circulation. Water vapor is transported along the river canyon from south to north, resulting in relatively abundant precipitation in the southeastern region. In addition, solid precipitation is an important component of the precipitation over the western area at high altitude [59]. The high precipitation concentration was mainly attributed to a few rainy days with large precipitation in the cold season.

The CI of most areas over the YTRB showed no significant trend during the study period, which agrees with the results of previous studies that were carried out in the adjacent regions. For example, most of the area of Xinjiang showed no significant trends in CI from 1961 to 2008 [15]. The decreasing trends in the CI of the Yangtze River Basin were not significant in most parts from 1960 to 2008 [63]. Overall, daily precipitation was generally more homogeneous in western China from 1961 to 2017 [28]. In the future, it is worth noting that the majority of stations in the YTRB will exhibit irregular and nonuniform distribution in precipitation during the dry season, which implies that the risk of environmental problems, such as flooding, soil erosion, and landslides, is likely to increase.

Some limitations and uncertainties inevitably exist due to the meteorological data and methods used in this study. The CI analysis using 16 stations in the basin was not fully representative of the spatial distribution of precipitation in the region. Precipitation data with a high 
spatiotemporal resolution is the basis for analyzing extreme climate events [57]. For instance, satellite-based precipitation is an alternative source of precipitation data [64]. Therefore, gridded precipitation data derived from merging gauge, satellite, and reanalysis data should be considered to promote thorough precipitation concentration research in the YTRB. In addition, the Hurst exponent was used to predict future trends of the CI. However, this method failed to predict how long the anticipated CI trend will continue. Given this, a climate model is a feasible and effective tool to study future precipitation concentration. Multimodel ensemble prediction may improve our understanding of future changes in precipitation extremes [9].

\section{Conclusions}

This study investigated the spatial distribution and changing trends of the daily precipitation concentration over the YTRB from 1970 to 2017. The CI values ranged from 0.58 to 0.65 , suggesting that a quarter of the rainiest days contributed approximately $69-78 \%$ of the total precipitation. Higher CI values were found in the western and eastern regions, while lower CI values were observed in the central region. The nonuniform distribution of rainfall was attributed to a large proportion of days with light rainfall. At a seasonal scale, the dry season was found to have a less homogeneous spatial distribution of CI. Most areas exhibited no significant trends in CI from 1970 to 2017. A quarter of the stations presented a significant downward trend of the CI, which were primarily found in the central and northern regions. The Hurst index analysis demonstrated that the precipitation concentration in the eastern and northern regions would decrease in the future, while the precipitation concentration in the southern and western regions will increase. The majority of stations in the YTRB exhibited an uneven precipitation distribution in the dry season, which implied that the risks of environmental problems, such as flooding, soil erosion, and landslides, are likely to increase. These results could provide useful information for water resource management, environmental risk management, and ecological conservation.

\section{Data Availability}

The data used in this paper were provided by the National Meteorological Information Center (http://data.cma.cn).

\section{Conflicts of Interest}

The authors declare that they have no conflicts of interest.

\section{Acknowledgments}

This research was supported by the National Natural Science Foundation of China (Grant no. 41661144044) and the National Key Research and Development Program of China (Grant no. 2016YFA0601601).

\section{References}

[1] A. Y. Hou, R. K. Kakar, S. Neeck et al., "The global precipitation measurement mission," Bulletin of the American Meteorological Society, vol. 95, no. 5, pp. 701-722, 2014.

[2] Q. Sun, C. Miao, Q. Duan, H. Ashouri, S. Sorooshian, and K. L. Hsu, "A review of global precipitation data sets: data sources, estimation, and intercomparisons," Reviews of Geophysics, vol. 56, no. 1, pp. 79-107, 2018.

[3] S. I. Bohnenstengel, K. H. Schlünzen, and F. Beyrich, "Representativity of in situ precipitation measurements-a case study for the LITFASS area in North-Eastern Germany," Journal of Hydrology, vol. 400, no. 3-4, pp. 387-395, 2011.

[4] S. Michaelides, V. Levizzani, E. Anagnostou, P. Bauer, T. Kasparis, and J. E. Lane, "Precipitation: measurement, remote sensing, climatology and modeling," Atmospheric Research, vol. 94, pp. 512-533, 2009.

[5] K. E. Trenberth, A. Dai, R. M. Rasmussen, and D. B. Parsons, "The changing character of precipitation," Bulletin of the American Meteorological Society, vol. 84, no. 9, pp. 1205-1218, 2003.

[6] L. V. Alexander, "Global observed long-term changes in temperature and precipitation extremes: a review of progress and limitations in IPCC assessments and beyond," Weather and Climate Extremes, vol. 11, pp. 4-16, 2016.

[7] M. G. Donat, O. Angélil, and A. M. Ukkola, "Intensification of precipitation extremes in the world's humid and water-limited regions," Environmental Research Letters, vol. 14, no. 6, p. 065003, 2019.

[8] J. Han, H. Du, Z. Wu, and H. S. He, "Changes in extreme precipitation over dry and wet regions of china during 19612014," Geophysical Research: Atmospheres, vol. 124, no. 11, pp. 5847-5859, 2019.

[9] C. Li, F. Zwiers, X. Zhang et al., "Larger increases in more extreme local precipitation events as climate warms," Geophysical Research Letters, vol. 46, no. 12, pp. 6885-6891, 2019.

[10] M. A. H. Mondol, M. Al, M. Iqbal, and D.-H. Jang, "Precipitation concentration in bangladesh over different temporal periods," Advances in Meteorology, vol. 2018, Article ID 1849050, 18 pages, 2018.

[11] G. Naveendrakumar, M. Vithanage, H.-H. Kwon, S. S. K. Chandrasekara et al., "South Asian perspective on temperature and rainfall extremes: a review," Atmospheric Research, vol. 225, pp. 110-120, 2019.

[12] R. Monjo and J. Martin-Vide, "Daily precipitation concentration around the world according to several indices," International Journal of Climatology, vol. 36, no. 11, pp. 3828-3838, 2016.

[13] M. S. Rahman and A. R. M. T. Islam, "Are precipitation concentration and intensity changing in Bangladesh overtimes? Analysis of the possible causes of changes in precipitation systems," Science of The Total Environment, vol. 690, pp. 370-387, 2019.

[14] R. J. Serrano-Notivoli, M. A. Saz, L. A. Longares et al., "Spatiotemporal variability of daily precipitation concentration in Spain based on a high-resolution gridded data set," International Journal of Climatology, vol. 38, pp. e518-e530, 2018.

[15] X. Li, F. Jiang, L. Li, and G. Wang, "Spatial and temporal variability of precipitation concentration index, concentration degree and concentration period in Xinjiang, China," International Journal of Climatology, vol. 31, no. 11, pp. 1679-1693, 2011.

[16] Q. Zhang, C.-y. Xu, M. Gemmer, Y. D. Chen, and C. Liu, "Changing properties of precipitation concentration in the 
pearl river basin, China," Stochastic Environmental Research and Risk Assessment, vol. 23, no. 3, pp. 377-385, 2008.

[17] J. E. Oliver, "Monthly precipitation distribution: a comparative index," The Professional Geographer, vol. 32, no. 3, pp. 300-309, 1980.

[18] L. Zhang and Y. Qian, "Annual distribution features of precipitation in China and their interannual variations," Acta Meteorologica Sinica, vol. 17, no. 2, pp. 146-163, 2003.

[19] J. Martin-Vide, "Spatial distribution of a daily precipitation concentration index in peninsular Spain," International Journal of Climatology, vol. 24, no. 8, pp. 959-971, 2004.

[20] B. Alijani, J. O’Brien, and B. Yarnal, "Spatial analysis of precipitation intensity and concentration in Iran," Theoretical and Applied Climatology, vol. 94, pp. 107-124, 2007.

[21] J. Suhaila and A. A. Jemain, "Spatial analysis of daily rainfall intensity and concentration index in Peninsular Malaysia," Theoretical and Applied Climatology, vol. 108, pp. 235-245, 2011.

[22] R. Coscarelli and T. Caloiero, "Analysis of daily and monthly rainfall concentration in Southern Italy (Calabria region)," Journal of Hydrology, vol. 416-417, pp. 145-156, 2012.

[23] A. Benhamrouche, D. Boucherf, R. Hamadache, L. Bendahmane, J. Martin-Vide, and J. Teixeira Nery, "Spatial distribution of the daily precipitation concentration index in Algeria," Natural Hazards and Earth System Sciences, vol. 15, pp. 617-625, 2015.

[24] R. Zamani, R. Mirabbasi, M. Nazeri, S. G. Meshram, and F. Ahmadi, "Spatio-temporal analysis of daily, seasonal and annual precipitation concentration in Jharkhand state, India," Stochastic Environmental Research and Risk Assessment, vol. 32, no. 4, pp. 1085-1097, 2017.

[25] P. Sarricolea, Ó. Meseguer-Ruiz, R. Serrano-Notivoli, M. V. Soto, and J. Martin-Vide, "Trends of daily precipitation concentration in Central-Southern Chile," Atmospheric Research, vol. 215, pp. 85-98, 2019.

[26] E. Vyshkvarkova, E. Voskresenskaya, and J. Martin-Vide, "Spatial distribution of the daily precipitation concentration index in Southern Russia," Atmospheric Research, vol. 203, pp. 36-43, 2018.

[27] P. Jiang, D. Wang, and Y. Cao, "Spatiotemporal characteristics of precipitation concentration and their possible links to urban extent in China," Theoretical and Applied Climatology, vol. 123, no. 3-4, pp. 757-768, 2015.

[28] J. Lu, Z. Jiang, L. Ren et al., "Spatial and temporal variability in precipitation concentration over mainland China, 19612017," Water, vol. 11, no. 5, p. 881, 2019.

[29] S. C. Kang, Y. W. Xu, Q. L. You, W. A. Flugel, N. Pepin, and T. D. Yao, "Review of climate and cryospheric change in the Tibetan Plateau," Environmental Research Letters, vol. 5, no. 1, 2010.

[30] Z. Liu, Z. Yao, H. Huang, S. Wu, and G. Liu, "Land use and climate changes and their impacts on runoff in the Yarlung zangbo river basin, China," Land Degradation \& Development, vol. 25, no. 3, pp. 203-215, 2014.

[31] M. Yang, S. Wang, T. Yao, X. Gou, A. Lu, and X. Guo, "Desertification and its relationship with permafrost degradation in Qinghai-Xizang (Tibet) plateau," Cold Regions Science and Technology, vol. 39, no. 1, pp. 47-53, 2004.

[32] J. Zhang, X. Shen, and B. Wang, "Changes in precipitation extremes in southeastern Tibet, China," Quaternary International, vol. 380-381, pp. 49-59, 2015.

[33] C. Liu, Y. Li, X. Ji, X. Luo, and M. Zhu, “Observed changes in temperature and precipitation extremes over the yarlung tsangpo river basin during 1970-2017," Atmosphere, vol. 10, p. $815,2019$.

[34] B. Li, W. Zhou, Y. Zhao et al., "Using the SPEI to assess recent climate change in the Yarlung zangbo river basin, south Tibet," Water, vol. 7, no. 10, pp. 5474-5486, 2015.

[35] J. Fan, W. Sun, Y. Zhao, B. Xue, D. Zuo, and Z. Xu, “Trend analyses of extreme precipitation events in the Yarlung zangbo river basin, China using a high-resolution precipitation product," Sustainability, vol. 10, no. 5, p. 1396, 2018.

[36] Y.-F. Sang, V. P. Singh, T. Gong et al., "Precipitation variability and response to changing climatic condition in the Yarlung Tsangpo River basin, China," Journal of Geophysical Research: Atmospheres, vol. 121, no. 15, pp. 8820-8831, 2016.

[37] Q. You, S. Kang, Y. Wu, and Y. Yan, "Climate change over the Yarlung zangbo river basin during 1961-2005," Journal of Geographical Sciences, vol. 17, no. 4, pp. 409-420, 2007.

[38] J. Liu, W. Zhang, T. Liu, and Q. Li, "Runoff dynamics and associated multi-scale responses to climate changes in the middle reach of the Yarlung zangbo river basin, China," Water, vol. 10, no. 3, p. 295, 2018 b.

[39] X. Ji, X. Luo, D. He et al., "Evaluation of bias correction methods for aphrodite data to improve hydrologic simulation in a large Himalayan basin," Atmospheric Research, vol. 242, Article ID 104964, 2020.

[40] J. Liu, Z. Xu, J. Bai, D. Peng, and M. Ren, “Assessment and correction of the persiann-CDR product in the Yarlung zangbo river basin, China," Remote Sensing, vol. 10, no. 12, p. 2031, 2018.

[41] Y. Masaki, N. Hanasaki, K. Takahashi, and Y. Hijioka, "Global-scale analysis on future changes in flow regimes using Gini and Lorenz asymmetry coefficients," Water Resources Research, vol. 50, no. 5, pp. 4054-4078, 2014.

[42] W. Shi, X. Yu, W. Liao, Y. Wang, and B. Jia, "Spatial and temporal variability of daily precipitation concentration in the Lancang River basin, China," Journal of Hydrology, vol. 495, pp. 197-207, 2013.

[43] C. Damgaard and J. Weiner, "Describing inequality in plant size or fecundity," Ecology, vol. 81, pp. 1139-1142, 2000.

[44] G. Kendall, Rank Correlation Methods, Griffin, London, UK, 4th edition, 1975.

[45] H. E. Hurst, "Long-Term storage capacity of reservoirs," Transactions of the American Society of Civil Engineers, vol. 116, no. 1, pp. 770-808, 1951.

[46] B. B. Mandelbrot and J. R. Wallis, "Robustness of the rescaled range $\mathrm{R} / \mathrm{S}$ in the measurement of noncyclic long run statistical dependence," Water Resources Research, vol. 5, no. 5, pp. 967-988, 1969.

[47] E. Guo, J. Zhang, Y. Wang et al., "Spatiotemporal variations of extreme climate events in Northeast China during 19602014," Ecological Indicators, vol. 96, pp. 669-683, 2019.

[48] P. Shi, M. Wu, S. Qu et al., "Spatial distribution and temporal trends in precipitation concentration indices for the Southwest China," Water Resources Management, vol. 29, pp. 3941-3955, 2015.

[49] J. Yuan, Y. Xu, L Wu et al., "Variability of precipitation extremes over the yangtze river delta, Eastern China, during 1960-2016," Theoretical and Applied Climatology, vol. 138, pp. 305-319, 2019.

[50] M. A. Sánchez Granero, J. E. Trinidad Segovia, and J. García Pérez, "Some comments on Hurst exponent and the long memory processes on capital markets," Physica A: Statistical Mechanics and Its Applications, vol. 387, no. 22, pp. 55435551, 2008. 
[51] Z. Liu, L. Tian, T. Yao, T. Gong, C. Yin, and W. Yu, "Temporal and spatial variations of $\delta 18 \mathrm{O}$ in precipitation of the Yarlung zangbo river basin," Journal of Geographical Sciences, vol. 17, no. 3, pp. 317-326, 2007.

[52] F. Li, Z. Xu, W. Liu, and Y. Zhang, "the impact of climate change on runoff in the yarlung tsangpo river basin in the Tibetan Plateau," Stochastic Environmental Research and Risk Assessment, vol. 28, no. 3, pp. 517-526, 2014.

[53] R. Wang, J. Zhang, E. Guo, C. Zhao, and T. Cao, "Spatial and temporal variations of precipitation concentration and their relationships with large-scale atmospheric circulations across Northeast China," Atmospheric Research, vol. 222, pp. 62-73, 2019.

[54] T. Caloiero, R. Coscarelli, and R. Gaudio, "Spatial and temporal variability of daily precipitation concentration in the Sardinia region (Italy)," International Journal of Climatology, vol. 39, no. 13, p. 5006, 2019.

[55] S. Mathbout, J. A. Lopez-Bustins, D. Royé, J. Martin-Vide, and A. Benhamrouche, "Spatiotemporal variability of daily precipitation concentration and its relationship to teleconnection patterns over the mediterranean during 1975-2015," International Journal of Climatology, vol. 40, no. 3, p. 1435, 2020.

[56] A. Vélez, J. Martin-Vide, D. Royé, and O. Santaella, "Spatial analysis of daily precipitation concentration in Puerto Rico," Theoretical and Applied Climatology, vol. 136, pp. 1347-1355, 2018.

[57] R. Zubieta, M. Saavedra, Y. Silva, and L. Giráldez, "Spatial analysis and temporal trends of daily precipitation concentration in the Mantaro River basin: central andes of peru," Stochastic Environmental Research and Risk Assessment, vol. 31, no. 6, pp. 1305-1318, 2017.

[58] N. Cortesi, J. C. Gonzalez-Hidalgo, M. Brunetti, and J. Martin-Vide, "Daily precipitation concentration across Europe 1971-2010," Natural Hazards and Earth System Sciences, vol. 12, no. 9, pp. 2799-2810, 2012.

[59] B. Bookhagen and D. W. Burbank, "Toward a complete Himalayan hydrological budget: spatiotemporal distribution of snowmelt and rainfall and their impact on river discharge," Journal of Geophysical Research Atmospheres, vol. 115, no. F3, 2010.

[60] N. Q. Qazi, S. K. Jain, R. J. Thayyen, P. R. Patil, and M. K. Singh, "Hydrology of the Himalayas," in Himalayan Weather and Climate and their Impact on the Environment, pp. 419-450, Springer, Cham, Switzerland, 2020.

[61] X. Luo, X. Fan, X. Ji, and Y. Li, "Evaluation of corrected aphrodite estimates for hydrological simulation in the yarlung tsangpo-brahmaputra river basin," International Journal of Climatology, vol. 40, no. 9, pp. 4158-4170, 2020.

[62] Y. Wang, K. Yang, X. Zhou et al., "The formation of a dry-belt in the north side of central himalaya mountains," Geophysical Research Letters, vol. 46, no. 5, pp. 2993-3000, 2019.

[63] W. Wang, W. Xing, T. Yang et al., "Characterizing the changing behaviours of precipitation concentration in the Yangtze River Basin, China," Hydrological Processes, vol. 27, no. 24, pp. 3375-3393, 2013.

[64] H. Beck, M. Pan, T. Roy et al., "Daily evaluation of 26 precipitation datasets using stage-iv gauge-radar data for the CONUS," Hydrology and Earth System Sciences Discussions, vol. 23, no. 1, pp. 207-224, 2018. 